\title{
Some Heterodox Analytic Philosophy
}

\author{
Guillermo E. Rosado Haddock
}

\begin{abstract}
Analytic philosophy has been the most influential philosophical movement in 20th century philosophy. It has surely contributed like no other movement to the elucidation and demarcation of philosophical problems. Nonetheless, the empiricist and sometimes even nominalist convictions of orthodox analytic philosophers have served them to inadequately render even philosophers they consider their own and to propound very questionable conceptions.
\end{abstract}

Keywords: Empiricism; Frege; Husserl; Carnap; model theory.

\section{Introduction}

Analytic philosophy has been without any doubt the most influential philosophical movement in $20^{\text {th }}$ century philosophy. In fact, it has most surely contributed like no other movement in the history of philosophy to the elucidation and demarcation of philosophical problems. Certainly, the self-imposed rigour of most analytic philosophy-with the exception of the English ordinary language philosophers, of which here nothing else will be said-and the use of logical tools in philosophy has without doubt elevated the discussion of philosophical problems in many areas of philosophy.

Nonetheless, the use of the word "analytic" in analytic philosophy is not uniformly applied. Analytic philosophy is usually traced back to Frege's views both on the philosophy of logic and mathematics, and to his semantic insights. Russell, Carnap, Quine and many leading figures of what could be called "orthodox analytic philosophy" see themselves as continuators of the same tradition inaugurated by Frege. However, such predominant trend in so-called analytic philosophy is permeated by a commitment to one or another sort of empiricism—and even nominalism—, which are totally foreign to Frege's views. In fact, the so-called Ockham's Razor, according to which one should not postulate the existence of entities that are not strictly indispensable, has been considered since Russell as the first commandment of orthodox analytic philosophy. Thus, in order to see Frege as their grandfather, empiricist philosophers had the extremely difficult task of trying to accommodate Frege's views to their ideology. Moreover, they felt compelled to reject any other philosopher or philosophical trend that could not be accommodated to their empiricist ideology. Hence, they both neglected valuable work that was not done by members of the empiricist church, while transforming, or better, deforming the philosophical work

Principia 17(2): 235-249 (2013).

Published by NEL — Epistemology and Logic Research Group, Federal University of Santa Catarina (UFSC), Brazil. 
of others in order to make it presentable to an empiricist audience. So was born the dichotomy between analytic and continental philosophy, the latter a sort of wastebasket in which the most dissimilar philosophical trends found their "final destination". In this sense, empiricists in philosophy are very similar to Marxist-leninists in the political arena: non-empiricist philosophers should not be read and if possible ostracized, very especially those concerned with similar issues, but under different presuppositions.

Such an attitude against other philosophical trends has both served orthodox analytic philosophers to give completely inadequate and even biased renderings of recent philosophers-even of those they consider their own-, and to propound conceptions that are clearly non-starters and that could very well had been prevented had they taken seriously philosophers they have preferred to ignore or to see through blinkers.

\section{Some Examples of Historical Distortions}

Let us begin with the so-called Duhem-Quine thesis. The first thing to be said about that thesis is that it lacks a referent. There is no such thing as the Duhem-Quine thesis. There is a very reasonable thesis of Duhem about the impossibility of isolating hypotheses in physics, with the immediate consequence of the non-existence of crucial experiments in physics. ${ }^{1}$ That thesis concerns exclusively physics, not even the other natural sciences, and, of course, does not concern logic or mathematics. It is based on the fact that to submit a physical hypothesis to experimentation and possible refutation the physicist needs to make use of instruments designed on the basis of physical laws. No matter how well established those laws are, it is not excluded that one of them is false and that the negative outcome of the experiment is due not to the hypothesis under scrutiny but to that law. In contrast with what happens in physics, in the other natural sciences one makes use of instruments not belonging to the same discipline but to physics and, thus, the biologist or physiologist makes an act of faith with regard to physics and is able to isolate the biological or physiological hypothesis from any law of the same discipline.

On the other hand, there is a completely unfounded thesis of Quine ${ }^{2}$ about the connection of all our beliefs in a so-called web of belief, according to which all statements, from the most trivial logical or arithmetical statements to statements such as that Newton had a toothache when he discovered the law of gravitation are connected, none of them is either analytic or a priori, thus, any of them can be refuted by experience, though we on purely pragmatic grounds prefer to save from refutation the logical and mathematical statements in the centre of our web of belief, while making those in the periphery responsible for any anomalies. Such an

Principia 17(2): 235-249 (2013). 
ungrounded thesis, instead of clarifying anything, serves only to add confusion. In fact, its origin is already doubtful, since it is based on Quine's so-called refutation of analyticity, which is basically restricted to the certainly very questionable Carnapian examples of presumed analytic statements like "All bachelors are not married". In fact, Quine's criticism of analyticity applies only to Carnap's definition of analyticity and, more specifically, to Carnap's unwarranted extension of his notion of analyticity to statements as the above, not to logical statements, and certainly not to Frege's, Husserl's or others' definitions of analyticity. We cannot dwell, however, on this issue here. It should be pointed out, nonetheless, that Quine's thesis under discussion has indirectly served to give life support to recent irrationalism in the form of postmodernism. Thus, it can be said that Quine is the grandfather or great-grandfather of post-modernism from the mother's side, while Nietzsche is the great-grandfather and Heidegger the grandfather of that sort of irrationalism from the father's side.

Our second example of a historical distortion is the common belief of analytic philosophers, based on assertions by E. W. Beth, Dagfinn Føllesdal ${ }^{3}$ and others that: (i) Husserl abandoned psychologism as a result of Frege's criticism, (ii) that in his Logische Untersuchungen he adhered to Frege's conception of logic, (iii) that Husserl learnt the sense-referent distinction from Frege, and (iv) that Husserl's notion of "noema" is a generalization of Frege's notion of sense. Since analytic philosophers usually do not read Husserl, they believe as religious fanatics the words of their prophets. The fact of the matter, however, is completely different. First of all, it should be stressed that Husserl did not obtain the sense-referent distinction present in Logische Untersuchungen from Frege. In fact, he had obtained that distinction in a paper written in 1890 and published only in 1970 as the second appendix to the Husserliana edition of his youth work Philosophie der Arithmetik under the title 'Zur Logik der Zeichen (Semiotik)' (Husserl 1890). Frege's first public mention of that distinction was in 'Funktion und Begriff' (Frege 1891) which appeared in January of 1891, when both Philosophie der Arithmetik and Husserl's review of the first volume of Schröder's book on the algebra of logic were in press (Husserl 1891b). In that review, which appeared with the book in March of 1891 the distinction between sense and referent (in its Husserlian version) is also present. Husserl sent immediately copies of the two writings to Frege, and Frege himself acknowledged that Husserl had obtained the distinction independently of him in a letter to Husserl of May of the same year, ${ }^{4}$ in which he discusses one of their differences, namely, that for Frege concepts were referents of conceptual words, whereas for Husserl they were senses of conceptual words (using Frege's better known terminology). There was another more important difference with respect to the referent of statements, but that does not concern us here.

Philosophie der Arithmetik was in some sense a dead born child. It was an extension of Husserl's professorship's thesis of 1887, and represented Husserl's views 
probably up to 1889 . Nonetheless, that youth book is not guilty of many of the exaggerations attributed to it by Frege in his late review of 1894. It contained a mild Brentanian psychologism that was supposed to be counterbalanced by a planned second volume concerned with logical foundations of arithmetic. The project of a second volume was abandoned probably a little after the publication of the first volume. If you examine Husserl's writings of that period, some important ones published only posthumously, as is the case of his Studien zur Arithmetik und Geometrie (Husserl 1983), you observe a constant evolution. ${ }^{5}$ In fact, already by 1894 - the year of Frege's infamous review-Husserl arrived at his mature view of logic and mathematics presented for the first time in his Logische Untersuchungen and since then maintained by him all his life. ${ }^{6}$ To say it very briefly, for him logic and mathematics were related not as mother and daughter but as sisters. Mathematics is not derived from logic, as in Frege's views, and logic is not ontological as is mathematics. Logic is a discipline in the realm of senses, that in its first level protects against nonsense, in its second level protects against countersense or contradiction, and in its third level is concerned with the notion of truth and similar semantic concepts, whereas mathematics is a formal ontology, a theory of structures with its mother structures as in the Bourbaki school, being the other mathematical structures either specializations of the most general structures, or combinations of them, or combinations of their specializations. Moreover, that ontological mathematics merges with logic in Husserl's version of the mathesis universalis, then crowning the edifice by a sort of theory of all possible theories. Such a conception of logic and mathematicsthe latter a generalization of Riemann's views ${ }^{7}$ and a forerunner of Bourbaki's (see Bourbaki 1950)—, has nothing to do with the much simpler Fregean conception.

A third case of historical distortion is the interpretation of Frege by Anglo-American scholars. According to the main trend in Fregean scholarship in English speaking countries, Frege was after all a Kantian or neo-Kantian, and primarily an epistemologist. $^{8}$ Such a rendering is based almost exclusively on the fact that Frege coincided with Kant with respect to his conception of geometry as a synthetic a priori science based on intuition. However, there end the coincidences. Even the arguments brought by Frege on behalf of his view of geometry are different from Kant's. Moreover, Frege forcefully rejects Kant's conception of arithmetic as synthetic a priori, and the central part of his work is concerned precisely with showing that his logicist views on arithmetic are correct and, hence, Kant's are false. ${ }^{9}$ Moreover, in multiple passages of his Die Grundlagen der Arithmetik and elsewhere Frege-who was primarily a philosopher of mathematics- makes it clear that he is a rationalist and Platonist in the best Leibnizian tradition (see Frege 1884 and 1918). Kant's mathematical constructivism, and the grounding of non-geometrical mathematics on the forms of sensibility of the human subject ${ }^{10}$ are completely foreign to Frege.

But a still more alienated rendering of Frege is that of Jamie Tappenden (see Tap-

Principia 17(2): 235-249 (2013). 
penden 1995, 2006), who conceives the history of mathematics in Germany in the nineteenth century as a cowboys versus Indians film. On the one hand, there are the cowboys - the good ones-of the Göttingen school founded by Gauß and presumably solidified by Riemann. On the other hand, there are the bad guys, the Indians, from the Berlin school of Weierstraß and Kronecker. Hence, since Frege studied in Göttingen (and also in Jena), he has to be somehow a Riemannian. Nonetheless, the fact of the matter is not only that Frege never referred to Riemann in his writingsand there is no evidence that Frege ever read Riemann's revolutionary monograph Über die Hypothesen, welche der Geometrie zugrude liegen-, and, moreover, Frege not only rejected non-Euclidean geometry in Die Grundlagen der Arithmetik for its lack of intuitivity, but in a posthumously published paper (Frege 1969) compared nonEuclidean geometry to alchemy and astrology, and wanted it ostracized from the scientific realm. On the other side of the coin were the poor Indians, Cantor, Husserl and Minkowski, who had the "misfortune" of having studied with Kronecker and very especially with chief Weierstraß. The case of Husserl is even worst, since he was also Weierstraß' assistant. Nonetheless, it was the Indian Husserl who was strongly influenced by Riemann, not only, as already mentioned, by developing a conception of mathematics as a generalization of Riemann's views, but by accepting already by the end of 1892 Riemann's conception of physical space as empirical, distinguishing with Riemann between the formal study of geometrical manifolds of any number of dimensions and curvature, and the investigations on the nature of physical space, which are and have to be empirical ${ }^{11}$ Hence, Husserl rejected already in 1892 Kant's aprioricity of both the three-dimensionality and the Euclidicity of space.

A last example of a historical distortion we want to discuss here is the case of the interpretations of Carnap's Der logische Aufbau der Welt, from now on Aufbau (Carnap 1928), and Husserl's influence on that book. The case of the young Carnap is certainly the most complex and delicate, since already in Aufbau and during the rest of his life Carnap himself deliberately tried to mask Husserl's influence. Only in his dissertation, Der Raum (Carnap 1922), published in 1922 is Husserl's influence perfectly acknowledged. In that small book Husserl is referred to many times and always positively. In fact, Der Raum was written by someone who, not only had a very good knowledge of Husserl's views, but by someone that at that moment considered himself Husserl's disciple. Nonetheless, in his so-called Intellectual Autobiography of 1963 (see Carnap 1963), Carnap says that it were Kant and the neo-Kantians, especially Natorp and Cassirer who exerted a decisive philosophical influence on Der Raum. It was Adolf Grünbaum, in his commentary on Der Raum in the same volume (Grünbaum 1963), who mentioned Husserl's influence on that small book and forced Carnap to accept in his 'Reply to Grünbaum'12 that besides Kant, Husserl also influenced his conception of intuitive space in Der Raum. But even that presumed acknowledgement was far from sufficient. As pointed out first by Sahotra Sarkar 
and then by the present author, Husserl was clearly the main philosophical influence on Der Raum and, moreover, though Kant is mentioned many times in the book, it is not always mentioned positively — as Husserl is-and sometimes seems to have been mentioned in order to appease Carnap's thesis director, the neo-Kantian Bruno Bauch, who probably was not especially fond of Husserl. On the other hand, the reference to Natorp and Cassirer is simply grotesque. ${ }^{13}$ They are barely mentioned, and when mentioned, together with Russell, on p.81 of Der Raum, only as philosophers that erroneously believed that the notions of Euclidean space and of homogeneous space are extensionally equivalent. Nonetheless, most Anglo-American Carnapian scholars still think that Kant and the neo-Kantians were the main influences on Der Raum.

With respect to Aufbau, in his Intellectual Autobiography Carnap says that the main influences were Frege and Russell (see p.12), the Gestalt psychology of Wertheimer and Köhler (see p.16-7), Ernst Mach, Richard Avenarius, Richard von Schubert-Soldern and Wilhelm Schuppe (see p.18), once more Mach and Russell (see p.50), and Mach, Russell and Wittgenstein (see p.57). Once more, Husserl is not even mentioned. In his commentary, Robert Cohen mentions Husserl's influence on Aufbau (see Cohen 1963), but this time in his 'Reply to Cohen' (Carnap 1963b, especially, p.863-7), Carnap completely ignores Cohen's remark. Moreover, on p.50 and on p.57 Carnap tries to make us believe that in Aufbau he took Ernst Mach's sense data as the basis of the system. This certainly contradicts what he said two years before on p.XII of the Preface to the second edition of Aufbau, namely, that he had taken the 'Erlebnisse' as the basis of his system and that if he had to write the book at that moment, that is, in 1961, he would have used instead a Machian basis, thus, clearly acknowledging that he did not use a Machian basis in Aufbau. In fact, he used a Husserlian basis, the elementary experiences of consciousness, the "Erlebnisse' in their constant flow in the stream of consciousness, in German: "Erlebnisstrom", ${ }^{14}$ though on p.16-7, in which he acknowledged the fact that he used Erlebnisse as basis-by the way contradicting his later assertions in the same 'Intellectual Autobiography'-he attributed the influence not to Husserl but to a paper of Wertheimer of 1925 and to one of Köhler of 1922. ${ }^{15}$ Moreover, Carnap not only based his constitutional system on a Husserlian basis, but (i) he used Husserl's argument - that Machian sense data are not given in experience but abstracted from what is given - to reject any Machian or Russellian basis, (ii) his notions of constitution and of grounding, in German: "Fundierung", are those of Husserl, (iii) his constitutional system is structured as a mirror image of Husserl's in the second volume of Ideen zu einer reinen Phänomenologie und einer phänomenologischen Philosophie, abbreviated: Ideen II (Husserl 1952), (iv) he committed himself to Husserl's phenomenological reduction, understood as in Husserl, as a methodological device, (v) his constitution of the heteropsychological is a mirror image of Husserl's attempt to 
solve the problem of intersubjectivity in Ideen II, in his Cartesianische Meditationen (Husserl 1928) and in his three volume posthumous work Zur Phänomenologie der Intersubjektivität (Husserl 1973). We could have mentioned other minor points of Husserl's influence on Carnap's Aufbau, but those six fundamental points are enough to prove that also in Aufbau Husserl was the main philosophical influence. Nonetheless, it should be pointed out that already in Aufbau Carnap consciously tries to mask Husserl's influence by usually referring to many different authors that barely have to do with Aufbau and including Husserl as one of the last in the list.

Once more Anglo-American Carnapian scholars have opted to ignore Husserl's influence on Aufbau, and tried either to argue that Mach and Russell were the most important influences on that book or, as has happened most recently, that Kant and the neo-Kantians were the main influences. ${ }^{16}$ The ignorance of Husserl's views, as well as some incredible blindness are the only grounds for such renderings, especially when there are passages in Aufbau in which Carnap explicitly rejects both empiricistpositivist views as well as neo-Kantian ones. We have already mentioned both that Carnap rejects a Machian-Russellian basis, and that he criticizes their views following Husserl's prior criticism of positivism. With respect to neo-Kantians, there is a very interesting passage (see Aufbau, p.87) in which Carnap includes neo-Kantians in a group of philosophers that-contrary to Carnap himself, Husserl and others-reject the autopsychological basis. He does not mention Kant, but even a very superficial examination of the latter's Kritik der reinen Vernunft should convince the sceptics that Kant's system has a heteropsychological basis, hence, one that was considered by Carnap a constitutional and epistemological non-starter. Furthermore, it should be mentioned that though Kant also uses the term 'constitution', he uses it precisely in the opposite sense of Husserl's and Carnap's usage in this context, namely, from the top to the bottom, not from the bottom to the top. Finally, the most decisive divergence between Husserl and Carnap, on the one side, and Kant, on the other, lies in the necessity of constituting the heteropsychological. For Kant that problem does not exist, since he presupposes the existence of other similarly endowed human beings. For Husserl and Carnap—as for Descartes—the allegiance to methodological solipsism forces them to tackle the problem of intersubjectivity (or heteropsychologicality), and their solution is the same.

In fact, Carnap's attitude towards Husserl not only borders on plagiarism, but is a clear case of dishonesty. Even the distinction between formation rules and transformation rules in Logische Syntax der Sprache was taken from Husserl, in this case from his opus magnum Logische Untersuchungen (see volume I, Chapter XI), as was also the distinction made in 'Überwindung der Metaphysik durch logische Analyse der Sprache' between two different types of nonsense (see volume II, Fourth Investigation). Moreover, it is not simply casual that Carnap was so strongly influenced by Husserl in his younger years. In fact, Carnap was Husserl's student, even if he was not 
honest enough to accept it. At least during three crucial semesters between 1924 and 1925 in which he was writing Aufbau the young doctor Carnap studied in Husserl's "Oberseminare", that is, seminars for doctor students and young doctors. ${ }^{17} \mathrm{He}$ was in especially friendly terms with the ten years younger Ludwig Landgrebe, ${ }^{18}$ who was Husserl's assistant during those years and worked precisely on the manuscripts that now constitute Ideen II. Moreover, there is the strong suspicion that Carnap had already met Husserl and probably visited Husserl's seminars while writing Der Raum, since while writing his dissertation (and also after his doctorate) he lived in Buchenbach in the outskirts of Freiburg, where Husserl was professor since 1916. Nonetheless, Carnap never publicly mentioned having studied with Husserl. Even in his Intellectual Autobiography he did not mention it, though he mentioned that he visited three of Frege's lecture courses. But anyone that knows something about the traditional German university system knows that when you visited a lecture course you did not have the least contact with the professor, you could not even ask a question, that is, your role was totally passive. On the other hand, it is in the seminars, especially in the "Oberseminare", that professors and students got acquainted with each other.

\section{Ignorance and Prejudice}

After 1926 when he went to Vienna Carnap seemed to have developed some sort of intellectual amnesia, not only with respect to Husserl's influence but also with respect to philosophical knowledge. Thus, he forgot Husserl's and his own criticism of Machian-Russellian positivist-empiricist views, and took active part in the discussion on protocol sentences, in which presumably one wanted the simple facts to speak for themselves be it in its physicalist or in its phenomenalist version. On the other hand, if Carnap and others had studied the non-empiricist Duhem carefully they would have not engaged in such a discussion about protocol sentences. As Duhem puts it (see, for example, Duhem 1894), in physical science there are certainly experiments, but they are not as simple and naive as the logical-positivists and, before them, for example, Claude Bernard, as mentioned by Duhem, believed. Even the simplest physical experiences in laboratory are theory-laden. What the physicist (or chemist) 'sees' in the laboratory is not what the layman casually invited to the laboratory observes. Such 'observations' are automatically interpreted by the specialist on the basis of theoretical knowledge serving as basis even in the design of the experiment. Such is the basis of the empirical knowledge used in the physical sciences, not the so-called protocol sentences, be it in their physicalist or in its phenomenalist version. The whole debate on protocol sentences was a complete waste of time.

Logical-positivists hoped that on the basis of the so-called protocol sentences they

Principia 17(2): 235-249 (2013). 
could obtain physical laws by induction, and in this way the verification of physical laws could be reduced to the direct verification of protocol sentences. It is unnecessary to mention here how trivial logical arguments destroyed the logical-positivists' program, as well as their variants using falsification or confirmation instead of verification, and even the more sophisticated Carnapian program of the observational and theoretical languages did not survive. In fact, already the design of the whole logical-positivist program, based on empiricist prejudices, was a non-starter, though the empiricist blinkers did not allow them to see it. A careful study precisely of Duhem's views on physical theories would probably have helped them discover their error (Duhem 1894, p.90-1). But what Duhem said about the theoretical nature of physical laws was not as clear and terse as what Husserl briefly said in Chapter IV and, especially, in Chapter XI of Logische Untersuchungen I. ${ }^{19}$ For Husserl, physics is an explanatory science and is a theoretical endeavour similar to mathematics, in which contrary to sciences like history, the decisive nexus is that of truths. Husserl clearly distinguishes between laws of low level, obtained more or less by some sort of induction, and genuine physical laws, which are of a theoretical nature and are called by Husserl "hypotheses cum fundamento in re". Husserl's preferred example of a hypothesis cum fundamento in re is Newton's law of gravitation. Such theoretical laws-in contrast to logical and mathematical laws, which are free of any link to experience-are linked, though only tenuously, to experience. They are not obtained by induction, but are introduced in order to explain the laws of low level originating in experience. By the way, Husserl obtained the deductive-nomological model for the explanation of laws of low level many years before Popper and Hempel. Such theoretical laws of higher level are not only tenuously linked to experience, but are in no way uniquely determined by the low level laws they are supposed to explain. There exists an indefinite number of possible hypotheses cum fundamento in re that could also explain the same low level law, that is, for example, hypotheses cum fundamento in re that are empirically equivalent to the law of gravitation but theoretically different from it. Thus, the laws of higher level are underdetermined by experience. Hence, Husserl obtained the underdetermination of physical theories-sometimes attributed to Quine-many decades before its introduction by analytic philosophers in the discussion of empirical theories. Once more, if logical-empiricists and other empiricist analytic philosophers had read Husserl carefully they would have avoided much effort that resulted in nothing fruitful.

\section{Empiricism, Nominalism and Logic}

We have already mentioned that very simple logic helped defeat the verificationism and its variants of logical positivism. But logical positivism was after all one of the most liberal versions of empiricism. One can very well suspect that other more

Principia 17(2): 235-249 (2013). 
radical forms of empiricism, for example Quine's or Mill's are non-starters in the philosophy of science and, generally, in philosophy. But paradoxically empiricists seem to be unable to learn from experience. Some of them have seen the Platonist demons in higher-order logic, and have tried to limit logic to first-order logic. They have found some comfort in adopting Quine's dictum that to be is to be the value of a quantified variable. Thus, since first-order logic quantifies only over individuals, you can continue being an empiricist and be a nominalist. In fact, empiricism and nominalism are near cousins.

Things, however, are not so smooth as nominalists and Quineans would like. First-order logic has by far the most developed semantics of any logic, and that semantics consists of structures and families of structures of all infinite cardinalities in virtue of Tarski's so-called Upward Löwenheim-Skolem Theorem. You do not quantify over them, but your whole first-order semantics presupposes their existence. By the way, Quine abandoned the nominalism of his younger years and accepted a sort of moderate realism for mathematical entities, according to which you have to acknowledge the existence of those mathematical entities postulated by mathematical theories applicable to physical science. Thus, the entities postulated by the remaining non-applied mathematics do not exist. Such a moderate physicalist realism of mathematical entities based on the so-called "indispensability argument" has, however, some difficulties. It has as a consequence that mathematical entities have properties very similar to living creatures, namely, they are born at a determinate temporal point and could very well die. Thus, tensors were born when Einstein and Hilbert independently of each other discovered the general theory of relativity. Other mathematical entities, for example, some abstract ones postulated by universal algebra or category theory have still not been born, though one can still hope that they will finally be born. For the moment, however, at least parts of those areas of mathematics are no more than a game similar to chess. On the other hand, if a mathematical theory ceases to be applied in physical science, the entities postulated by that theory would die. I consider all those consequences of Quine's moderate realism absurd enough, so that the theory itself does not merit further consideration.

But certainly among empiricists there are more consistent and staunch nominalists that would not accept even Quine's moderate realism. However, if you are a true nominalist and do not accept the existence of mathematical entities, then you have to consider any existential statement purporting to talk about mathematical entities as false and universal statements purporting to talk about mathematical entities as vacously true. Nonetheless, there is an important theorem in classical first-order model theory, namely, Robinson's Model-Completeness Test, which states, among other things, that a theory is model-complete-that is, substructures of models of the theory are always elementary substructures - if and only if for any existential statement in the language of the theory, there exists a universal statement in the 
same language that is equivalent to it. Hence, if an existential statement is false, then there is a universal one equivalent to it and, thus, false, and, conversely, their negations, which are respectively equivalent to a universal and to an existential statement, are true. Thus, there are true existential statements. Therefore, in virtue of the Model-Completeness Test, nominalism is false. Moreover, once more in virtue of the Model-Completeness Test, conventionalism in mathematics is also false, since one cannot make all existential statements false and all universal statements true, or the other way around. As a corollary, one can also conclude that Carnap's Principle of Tolerance, according to which, among other things, you are in complete liberty to choose a Platonist or a nominalist language, is also refuted. Classical (first-order) model theory is incompatible with the Principle of Tolerance.

Finally, among empiricists there have been some that have tried to argue on behalf of first-order logic and against second- and higher-order logic by referring to some desirable properties of first-order logic and contrasting the latter with the lack of such properties in higher-order logic. Let us examine some of those arguments. They certainly cannot reasonably refer to the fact that first-order logic has a very rich model theory, because that model theory consists precisely of abstract structures of any infinite cardinality. They can, however, refer to semantic completeness, the fact that first-order syntax is capable of properly covering first-order semantics, whereas that is not the case with classical-I would say "genuine"second-order logic. Nonetheless, decidability and categoricity are also very desirable meta-mathematical properties, but first-order logic-except for its small monadic segment-is not decidable, whereas mathematical theories that are usually categorical are not categorical when expressed in the language of first-order logic. Those theories are, however, categorical when expressed in second-order logic. No matter what the defenders of first-order logic say, that is a clear sign of the inadequacy to express mathematical theories in first-order logic. Hence, one has to balance the positive and negative aspects of both logics without blinkers when comparing them and should not be in any hurry to condemn second-order logic.

Another popular argument wielded by defenders of first-order logic against second-order logic is that the former has only one semantics, whereas the latter has multiple semantics. Presumably, second-order logic allows besides its classical semantics a multi-sorted semantics and Henkin's semantics, which admits truncated models and served him to obtain a Weak Semantic Completeness Theorem. Nonetheless, ${ }^{20}$ once more one should not hurry to conclusions and interpret such presumed facts as a clear victory for first-order logic. In fact, there is no victory at all. Many-sorted second-order semantics is equivalent to Henkin's deviant semantics, ${ }^{21}$ thus, reducing the number of semantics for second-order logic to two. Moreover, Henkin's semantics for second-order logic was introduced in order to prove the Weak Semantic Completeness Theorem. But once you have semantic completeness, you can obtain, 
as corollaries both the Compactnes Theorem and the Downward Löwenheim-Skolem Theorem. There is, however, an extremely important result in abstract model theory, namely, Lindström's First Characterization Theorem, ${ }^{22}$ which states that any extension of first-order logic for which both the Compactness Theorem and the Downward Löwenheim-Skolem Theorem are valid is equivalent to first-order logic. Hence, what Henkin's Weak Semantic Completeness Theorem accomplishes is a reduction of second-order logic to first-order logic. Therefore, it is not the case that second-order logic properly has a diversity of semantics. The argument against second-order logic based on the multiplicity of semantics has been refuted.

\section{References}

Beth, E. W. 1965. The Foundations of Mathematics. Amsterdam: North Holland.

Bourbaki, N. 1950. The Architecture of Mathematics. American Mathematical Monthly 57: 221-32.

Carnap, R. 1922. Der Raum. Vaduz: Topos Verlag (reprint 1991).

— 1928. Der logische Aufbau der Welt. 2nd ed. Hamburg: Felix Meiner, 1961.

- 1932. Überwindung der Metaphysik durch logische Analyse der Sprache. Reprinted in Scheinprobleme in der Philosophie und andere metaphysikkritische Aufsätze. Hamburg: Felix Meiner, 2004, p.81-109.

- 1934. Logische Syntax der Sprache. Enlarged English edition, London: Routledge, 1937.

1963a. Intellectual Autobiography. In: Schilpp 1963, p.3-84.

1963b. Replies and Systematic Expositions. In: Schilpp 1963, p.859-1013.

Church, A. 1944. Introduction to Mathematical Logic. Princeton: Princeton University Press (enlarged edition, 1956).

Cohen, R. 1963. Dialectical Materialism and Carnap's Logical Empiricism. In: Schilpp 1963, p.99-158.

Duhem, P. 1894. Some Reflections on the Subject of Experimental Physics. French original, 1894, translated in Duhem 1996, p.75-111.

- 1914 [1955, 1991] La Théorie Physique, son Objet, sa Structure. English translation, The Aim and Structure of Physical Theory. Princeton: Princeton University Press.

- 1996. Essays in the History and Philosophy of Science. Edited by Roger Ariew and Peter Baker. Indianapolis: Hackett.

Field, H. 1980. Science without Numbers. Oxford: B. H. Blackwell.

. 1989. Realism and Antirealism about Mathematics. In H. Field: Realism, Mathematics and Modality. Oxford: B. H. Blackwell, p.53-78.

Føllesdal, D. 1958. Husserl und Frege, ein Beitrag zur Beleuchtung der phänomenologischen Philosophie. English translation in: L. Haaparanta (ed.) Mind, Meaning and Mathematics. Dordrecht: Kluwer, 1994, p.3-47

- 1969. Husserl's Concept of Noema. Journal of Philosophy 66(20): 680-97.

Frege, G. 1884 [1986]. Die Grundlagen der Arithmetik. Centenary edition. Hamburg: Felix Meiner.

Principia 17(2): 235-249 (2013). 
- 1891. Funktion und Begriff. Reprinted in Frege 1967, p.125-42.

- 1894. Rezension von: E. G. Husserl, Philosophie der Arithmetk I. Reprinted in Frege 1967, p.179-92.

- 1918. Der Gedanke. Reprinted in Frege 1967, p.342-62.

—. 1967 [1990]. Kleine Schriften. Revised edition. Hamburg: Felix Meiner.

- 1969. Über Euklidische Geometrie. In: Frege 1969, p.182-4

— 1969 [1983]. Nachgelassene Schriften, revised edition. Hamburg: Felix Meiner.

- 1974a. Wissenschaftlicher Briefwechsel. Hamburg: Felix Meiner.

- 1974b. Brief an Husserl vom 24ten Mai 1891. In: Frege 1974, p.94-8.

Friedman, M. 1999. Reconsidering Logical Positivism. Cambridge: Cambridge University Press. Grünbaum, A. 1963. Carnap's Views on the Foundations of Geometry. In: Paul A. Schilpp (ed.) 1963, p.599-684.

Husserl, E. 1887. Über den Begriff der Zahl. Reprint as Appendix A in Hua XII, p.289-339. . 1890. Zur Logik der Zeichen (Semiotik). In: Hua XII, p.340-73. Den Haag: Martinus Nijhoff, 1970.

- 1891a. Philosophie der Arithmetik. In: Hua XII. Den Haag: Martinus Nijhoff, 1970. .1891b. Beschprechung von E. Schröders Vorlesungen über die Algebra der Logik I. Reprinted in: Aufsätze und Rezensionen (1890-1910), Hua XXII. Den Haag: Martinus Nijhoff, p.3-43.

—. 1900-1901. Logische Untersuchungen. 2 vols. Hua XVIII and Hua XIX. Den Haag: Martinus Nijhoff, 1975 \& 1984.

- 1913. Ideen zu einer reinen Phänomenologie und einer phänomenologischen Philosophie I. Hua III, 1950, revised edition 1976. Den Haag: Martinus Nijhoff.

—. 1928. Cartesianische Meditationen. Hua I. Den Haag: Martinus Nijhoff, 1950.

- 1929. Formale und transzendentale Logik. Hua XVII. Den Haag: Martinus Nijhoff, 1974.

- 1952. Ideen zu einer reinen Phänomenologie und einer phänomenologischen Philosophie II. Hua IV. Den Haag: Martinus Nijhoff.

—. 1973. Zur Phänomenologie der Intersubjektivität. 3 vols. Hua XIII-XV. Den Haag: Martinus Nijhoff.

- 1975. Introduction to the Logical Investigations. Den Haag: Martinus Nijhoff.

- 1983. Studien zur Arithmetik und Geometrie. Hua XXI. Den Haag: Martinus Nijhoff.

- 1984. Einleitung in die Logik und Erkenntnistheorie. Hua XXIV. Den Haag: Martinus Nijhoff.

Kant, I. 1781. Kritik der reinen Vernunft. Revised edition 1787, reprint of both versions, edited by R. Schmidt, Hamburg: Felix Meiner, 1930, third edition 1990.

Lindström, P. 1974. On Characterizing Elementary Logic. In: S. Stenlud (ed.) Logical Theory and Semantic Analysis. Dordrecht: Reidel, p.129-46.

Manzano, M. 1996. Extensions of First Order Logic. Cambridge: Cambridge University Press.

Richardson, A. 1998. Carnap's Construction of the World. Cambridge: Cambridge University Press.

Rosado Haddock, G. E. 2006. A Critical Introduction to the Philosophy of Gottlob Frege. Aldershot: Ashgate.

- 2008. The Young Carnap's Unknown Master. Aldershot: Ashgate.

- 2012a. Against the Current. Frankfurt: Ontos Verlag.

Principia 17(2): 235-249 (2013). 
2012b. On the Interpretation of Frege's Philosophy. In: Rosado Haddock 2012a, p.21-62.

Schilpp, P. A. (ed.) 1963. The Philosophy of Rudolf Carnap. La Salle: Open Court.

Schuhmann, K. 1977. Husserl-Chronik. Den Haag: Martinus Nijhoff.

Tappenden, J. 1995. Geometry and Generality in Frege's Philosophy of Arithmetic. Synthese 102(3): 319-61.

2006. The Riemannian Background of Frege's Philosophy. In J. Ferreiros and J. Gray (eds.), The Architecture of Modern Mathematics. Oxford: Oxford University Press, p.97132.



Resumo. A filosofia analítica foi o movimento filosófico mais influente na filosofia do século XX. Esse movimento certamente contribuiu como nenhum outro para a elucidação e demarcação de problemas filosóficos. Contudo, as convicções empiristas e, por vezes mesmo nominalistas, dos filósofos analíticos ortodoxos levou-os a representar inadequadamente mesmo filósofos que consideram de sua tradição, bem como a propor concepções bastante questionáveis.

Palavras-chave: Empirismo; Frege; Husserl; Carnap; teoria de modelos.

\section{Notes}

${ }^{1}$ See on this issue Duhem's paper 'Some Reflections on the Subject of Experimental Physics' (Duhem 1894), especially p.81-8, as well as his book La Théorie Physique: son Objet, sa Structure (Duhem 1914).

${ }^{2}$ See his 'Two Dogmas of Empiricism', 1951, reprinted in From a Logical Point of View, p.2046.

${ }^{3}$ Certainly, the objective of Føllesdal, a renowned Husserl scholar who has certainly contributed to making Husserl known to analytic philosophers, were very different from those of other scholars trying to dismiss or disqualify Husserl. By the way, it should be pointed out that both Føllesdal's and Beth's contentions precede the publication in 1970 and 1975 of two writings of Husserl of decisive importance in this controversy-see footnotes 4 and 9 below. ${ }^{4}$ See his Wissenschaftlicher Briefwechsel (Frege 1974a), p.94-8.

${ }^{5}$ For the intellectual development of Husserl from Philosophie der Arithmetik to Logische Untersuchungen see Husserl's Introduction to the Logical Investigations 1975.

${ }^{6}$ See Logische Untersuchungen 1900-1901, Chapter XI, as well as his Formale und transzendentale Logik (1929), where the semantic level is neatly demarcated from the logicalsyntactic level, to use Carnap's later terminology, and the posthumously published Einleitung in die Logik und Erkenntnistheorie (1984).

Principia 17(2): 235-249 (2013). 
${ }^{7}$ See his classic monograph 'Über die Hypothesen, welche der Geometrie zugrunde liegen' 1867, third edition, Berlin 1923, reprint Chelsea, New York 1973.

${ }^{8}$ For a critical assessment of the thesis-not discussed here-that Frege was an epistemologist, see the present author's paper (Rosado Haddock 2012b).

${ }^{9}$ For Frege's views on arithmetic and geometry see his Die Grundlagen der Arithmetik, especially the first part. See also $\S 2$ of the present author's 'On the Interpretation of Frege's Philosophy' (Rosado Haddock 2012b).

${ }^{10}$ See Kant's Kritik der reinen Vernunft, especially the Transcedental Aesthetic and the first part of the Doctrine of Method.

${ }^{11}$ See Husserl's letter to Brentano of 29 December 1892 in Briefwechsel I, p.8-11, as well as his letters to Natorp of 29 March 1897 and of 7 September 1901, also in Briefwechsel I, p. 59-64 and 80-86, respectively.

12 See his 'Replies and Systematic Expositions' (Carnap 1963b), especially, p.952-58.

${ }^{13}$ In 1911 Husserl was by far the first candidate to occupy a position of full professor at the University of Jena, but for still unclear reasons the full professorship was given to the clearly inferior Bauch instead of to the author of Logische Untersuchungen, who in 1913 published his Ideen zu einer reinen Phänomenologie und einer phänomenologischen Philosophie I and in 1916 succeeded Bauch's teacher Rickert in Freiburg.

14 On this and other points below see Husserl's Ideen I (1913).

${ }^{15}$ It is simply ridiculous to attribute such an influence to a paper published in 1925, when Aufbau was been finished, and even to one of 1922, after having referred to Husserl's Ideen I in Der Raum. The fact of the matter is that Gestalt psychologists-like Wertheimer and Köhler-most probably also obtained those concepts from Husserl.

${ }^{16}$ See Friedman's and Richardson's books included in the references.

17 See on this issue, Karl Schuhmann's Husserl-Chronik, p.281, where he refers to a letter of 6 August 1976 sent to him by Ludwig Landgrebe, in which the latter mentions that Carnap took part in Husserl's seminars from the summer semester of 1924 to the summer semester of 1925.

${ }^{18}$ See Landgrebe's letter to Husserl of 11 November 1932 in Husserl's Briefwechsel IV, p.298.

${ }^{19}$ Logische Untersuchungen I, Chapter IV, §23 and Chapter XI, §§62-66.

${ }^{20}$ For a detailed treatment of this theorem see Chapter V of Alonzo Church's Introduction to Mathematical Logic (Church 1944).

${ }^{21}$ See, for example, María Manzano's book Extensions of First Order Logic (Manzano 1996).

${ }^{22}$ See, for example, Lindström's paper 'On Characterizing Elementary Logic' (1974).

Principia 17(2): 235-249 (2013). 